\title{
O fenômeno da transmissão psíquica e o incesto: possíveis articulações
}

The phenomenon of psychic transmission and incest: possible articulations

El fenómeno de la transmisión psíquica y el incesto: las posibles conexiones

\author{
Anna Thereza Carneiro Pinto Abdala* \\ Anamaria Silva Neves** \\ João Luiz Leitão Paravidini**
}

\begin{abstract}
Resumo
Este artigo tem como objetivo tecer considerações em relação aos processos de transmissão psíquica, tomando como hipótese básica que o incesto como um sintoma dos legados da herança psíquica na composição do espaço intersubjetivo da família. Foi construído um caminho teórico, iniciado a partir dos escritos de Freud, sobre a transmissão psíquica e seus conteúdos, e, posteriormente, somaram-se contribuições de autores contemporâneos em relação ao tema proposto. Diante das reflexões elaboradas (considerando desde os primórdios da civilização e a criação dos tabus fundamentais com a horda primeva), foi possível apreender que a transmissão psíquica é um elemento presente na dinâmica da família incestuosa. Além disso, é importante considerar que o mito familiar e o pacto denegativo contribuem para a repetição do incesto nas gerações das famílias, auxiliando na manutenção dos vínculos do grupo familiar.
\end{abstract}

Palavras-chave: Transmissão psíquica. Incesto. Mito familiar. Pacto denegativo.

\begin{abstract}
This article intents to build upon ideas related to the process of psychic transmission, trying to state that incest is a symptom derived from the legacies of psychic heritage in the composition of the inter-subjective space of the family. The theory followed a path that started with the works of Freud about psychic transmissions and later, added to the
\end{abstract}

\footnotetext{
Mestranda no Programa de Pós-Graduação em Psicologia Aplicada da Universidade Federal de Uberlândia, psicóloga graduada pela mesma universidade. E-mail: annathe_abdala@yahoo.com.br.

* Doutora em Psicologia pela Universidade de São Paulo, professora adjunta do Instituto de Psicologia da Universidade Federal de Uberlândia. E-mail: anamaria@umuarama.ufu.br. Endereço para correspondência: Universidade Federal de Uberlândia, Instituto de Psicologia. Av. Pará, no 1720, Bloco C - Jardim Umuarama, Uberlândia-MG, Brasil. CEP: 38405318. Telefone: (34) 3218-2235, ramal 31.

*** Doutor em Ciências Médicas pela Universidade Estadual de Campinas, professor associado do Instituto de Psicologia da Universidade Federal de Uberlândia. E-mail: jlparavidini@gmail.com.
} 
contributions of contemporary authors who worked with this subject. From the reflections on the subject - considered since the beginnings of civilization and the creation of important taboos within the prime horde - it was possible to learn that psychic transmission is an element that exists in an incestuous family. Besides, it is interesting to consider that the family myth and the denied pact contribute to the frequency of incest in the family generations, helping in the maintaining of bonds within the family group.

Keywords: Psychic transmission. Incest. Family myth. Denied pact.

\section{Resumen}

Este artículo tiene como objetivo construir ideas relacionadas con el proceso de la transmisión psíquica, considerando como hipótesis básica el incesto como un síntoma de los legados de la herencia psíquica en la composición del espacio intersubjetivo de la familia. La teoría vino a través de un camino que se inició en las obras de Freud sobre la transmisión psíquica y sus contenidos, y más tarde, se sumaron los aportes de autores contemporáneos que han trabajado con este tema. Ante las reflexiones elaboradas (teniendo en cuenta los inicios de la civilización y de la creación de tabúes fundamentales con la horda primordial) fue posible aprender que la transmisión psíquica es un elemento que existe en la dinámica de la familia incestuosa. Además, es interesante tener en cuenta que el mito familiar y el pacto negado contribuyen a la repetición del incesto en las generaciones de las familias, ayudando a mantener los vínculos en el grupo familiar.

Palabras clave: La transmisión psíquica. Incesto. Mito familiar. Pacto negado.

\section{Introdução}

interesse em escrever sobre o tema da transmissão psíquica surge a
partir de leituras dos escritos de Freud e de situações clínicas de autores
contemporâneos, nas quais aparecem aspectos sem representação que
formam obstáculos para a compreensão da dinâmica do psiquismo do sujeito.

Freud afirma:

Podemos presumir com segurança que nenhuma geração pode ocultar à geração que a sucede nada de seus processos mentais mais importantes, pois a psicanálise nos mostrou que todos possuem, na atividade mental inconsciente, um apparatus que os capacita a interpretar as reaçóes de outras pessoas, isto é, a 
desfazer as deformações que os outros impuseram à expressão de seus próprios sentimentos (Freud, 1974c, p. 188).

Nesse trecho, Freud afirma a existência do fenômeno da transmissão psíquica, ainda que ele não tenha usado essa nomenclatura. Em trabalhos posteriores, Freud (2010b; 2011a; 1974b) passa a usar a expressão "herança arcaica”. Este é um assunto pelo qual a psicanálise se interessa desde seus primórdios e se aplica também a situações clínicas contemporâneas, nas quais os impasses para compreender o sujeito implicam considerar aquilo que lhe é anterior.

A herança psíquica, fator enriquecedor para investigar as facetas do sofrimento psíquico, é um fenômeno, de acordo com Silva (2003), resultante do processo de transmissão psíquica, que contém conteúdos intergeracionais e transgeracionais, apreendidos na clínica psicanalítica por meio das manifestações sintomáticas.

O processo de transmissão psíquica tem participação fundamental na composição da subjetividade, ressaltando que a cultura, linguagem, leis constituintes da civilização também são transmitidos parcialmente pela via desse fenômeno, assim como os objetos transgeracionais que podem se originar de sentimentos de culpa, fantasias, desejos, recalcamentos, lutos não elaborados, condiçôes narcísicas, os quais se tornam aspectos sem representação que compõem o espaço intrapsíquico familiar e do sujeito (Kaës, 1998; Silva, 2003).

Este estudo teórico tem como objetivo tecer consideraçôes e reflexôes a respeito dos processos de transmissão psíquica na constituição do psiquismo do sujeito, construindo uma metapsicologia do tema em questão, articulando inicialmente aspectos da transmissão psíquica que Freud postulou em suas obras. A hipótese básica é pensar o incesto, em alguns aspectos, como possível sintoma dos legados da herança psíquica na composição do espaço intersubjetivo da família.

\section{As contribuiçõos de Freud para a discussão da transmissão psíquica}

Freud (1974a) fala sobre algo que influencia a conduta dos seres humanos, seus pensamentos e associaçóes: as representaçóes inconscientes, as quais, mesmo sendo presentes com frequência, são inadmissíveis à consciência. Freud já aponta o inconsciente como regente do sujeito, o qual, muitas vezes, não tem conhecimento disso. Além disso, o autor chama atenção para a questão da hereditariedade de aspectos psíquicos em relação àquilo que é transmitido 
inconscientemente por entre as gerações das famílias e nas posiçóes que os seus membros ocupam na dinâmica.

Antes de prosseguir, é importante fazer uma ressalva no que diz respeito à palavra transmissão. Esta aparece no sentido inconsciente, ou seja, os sujeitos não optam por algo a ser herdado, não há escolha, fazendo da transmissão psíquica algo que é posto desde os primórdios da civilização (Freud, 1974c).

Com base nas ideias freudianas, é possível pensar, como exemplos de transmissões entre as geraçôes, os tabus fundamentais para a permanência da civilização: a interdição do incesto e a proibição de matar o pai. Tabu significa algo sagrado, mas também impuro e perigoso; é estabelecido como regra social e cultural a ser seguida pelos sujeitos pertencentes a um grupo.

Pode-se explicar a instituição dos tabus constituintes da civilização, de acordo com Freud (1974c), com base no mito da horda primeva. O autor a descreve como sendo composta por um pai violento, também líder do grupo, que podia exercer a poligamia, além do incesto contrariamente às regras impostas aos outros integrantes, por exemplo, os filhos. O líder, receoso de que os filhos se tornassem suficientemente fortes para tomar seu lugar e diante das investidas libidinais deles às mulheres do bando, os expulsa da horda. Tomados pelo desejo de destituir o poder do pai, os irmãos se unem, assassinando-o e devorando-o. Este último ato leva a uma identificação ${ }^{1}$ com o pai como se cada um adquirisse parte de sua força.

A ambivalência entre amor e ódio em relação a esse pai fez surgir um sentimento de culpa, e "o pai morto tornou-se mais forte do que o fora vivo" (Freud, 1974c, p. 171). E, assim, os próprios filhos, diante do sentimento de culpa, proibiram a morte do totem, substituto do pai, e renunciaram às mulheres do bando desejadas por eles anteriormente, barrando a prática do incesto.

Essas leis originárias na Antiguidade primeva também podem ser compreendidas como tradições, já que vão sendo transmitidas entre as gerações e são necessárias para a continuidade da civilização. Essa transmissão psíquica ocorre por via da identificação com os modelos parentais na história do sujeito e também da autoridade social relativa ao grupo e ao modo que este foi composto e instituído (Freud, 1974c; 2011b).

Identificação é um processo psíquico em que o sujeito assimila uma característica, um traço do outro e se modifica, em algum(ns) aspecto(s), de acordo com o modelo desse outro sujeito (Freud, 2011b). Faz-se necessária essa definição devido a esse conceito ser essencial para a discussão dos processos de transmissão psíquica. 
As identificações advindas das relações primeiras podem se sustentar em diversos caminhos, como o da constituição da forma original de laço emocional com um objeto. A identificação, de maneira regressiva,

Se torna o substituto para uma ligação objetal libidinosa, como que através da introjeção 2 do objeto no $\mathrm{Eu} ;[. .$.$] ela pode$ surgir a qualquer nova percepção de algo em comum com uma pessoa que não é objeto dos instintos sexuais. Quanto mais significativo esse algo em comum, mais bem-sucedida deverá ser essa identificação parcial, correspondendo assim ao início de uma nova ligação (Freud, 2011b, p. 65).

Os modelos de identificação (objetos de amor e ódio) dos sujeitos serão os próprios membros da família e de outros grupos a que pertencerem (Freud, 2011b). Para a Psicanálise, as relaçôes amorosas íntimas que perduram, sejam estas amizades, casamentos, relacionamentos entre pais e filhos, contêm, além de sentimentos positivos para as relações, um depósito daquilo que é aversivo e hostil, e estes escapam de serem percebidos devido ao mecanismo de repressão.3

Essas relações entre os sujeitos são permeadas por sonhos, fantasias, segredos, lutos, desejos. Todos esses elementos, que podem ou não ter peculiaridades secretas e ocultas, influenciam inconscientemente no movimento da formação de algo no psiquismo do sujeito: o objeto a ser transmitido por meio do processo de identificação.

Entre as diversas estruturas psíquicas que se formam e predominam nas relações, toma-se como exemplo as narcísicas, as quais alguns pais podem estabelecer com seus filhos, revivendo o próprio narcisismo (outrora abandonado) perante suas atitudes para com a criança. Freud (2010c) coloca que a supervalorização dos pais para com os filhos é algo que domina a relação entre eles. "Os pais são levados a atribuir à criança todas as perfeições - que um observador neutro nelas não encontraria - e a ocultar e esquecer todos os defeitos" (p. 36), ou seja, as figuras parentais não mencionam as falhas e faltas das crianças, nem as deles, como se fosse possível não tê-las.

Os pais, que constroem essas relações narcísicas, têm a ideia de que "as coisas devem ser bem melhores para a criança [...], ela não deve estar sujeita às necessidades que reconhecemos como dominantes na vida" (Freud, 2010c, p.

\footnotetext{
2 Introjeção é um conceito originalmente criado por Ferenczi (1988). Pode ser entendido como um processo psíquico posterior à identificação no qual o objeto, anteriormente assimilado, passa a compor a psique do sujeito.

3 A repressão é um mecanismo de defesa que essencialmente tenta "rejeitar e manter algo afastado da consciência" (Freud, 2010a, p. 85), fazendo com que representantes psíquicos das pulsões ou associações referentes a estes permaneçam reprimidas no inconsciente. O uso do termo repressão está de acordo com a tradução da obra freudiana utilizada.
} 
37). Esse modo de agir faz com que o filho seja privado do contato com noções de doença, morte, renúncia ao prazer, restrições de vontades e não desenvolva tolerância à frustração, pois tudo é possível de se realizar no momento em que se deseja, revivendo a condição suprema de "Sua Majestade, o Bebê" (p. 37) (o centro e âmago da criação).

Freud (2010c) também menciona os desejos dos pais de que os filhos consigam realizar os sonhos e projetos não alcançados por eles mesmos. Tais desejos são investimentos libidinais e, ao mesmo tempo, narcísicos, que podem somar-se a outros fatores e constituir uma possível herança psíquica a ser transmitida ao filho. Caso isso ocorra, o lugar da criança nessa família seria de um possível depositário e herdeiro de sonhos e desejos parentais.

A expressão herança psíquica nem sempre foi designada como é conhecida e empregada atualmente. Quando Freud (2010b) discutiu os processos de transmissão psíquica de uma forma mais detalhada, denominou de "herança arcaica" o resultado destes. $\mathrm{O}$ autor entende que essa é constituinte do núcleo dos processos psíquicos inconscientes. Ele argumenta que, independentemente de aspectos dessa herança que se fixem na continuidade do desenvolvimento, seja por fatores prejudiciais, por não serventia ou ainda incompatibilidade com o novo, o mecanismo de repressão passará a ter papel fundamental, já que este, por vezes, não permite que conteúdos inconscientes revelem algo, por exemplo, que o sujeito desconhece da própria história e tem relação com um possível sintoma.

É importante considerar também a articulação que Freud (2011a) fez entre a herança arcaica e sua vinculação com as instâncias psíquicas: id, eu e supereu. $\mathrm{O}$ autor postula que o eu é o que constitui vínculos mais abundantes com a herança arcaica, o que se deve à maneira pela qual o ideal do eu é formado.

Freud (2011a) ainda versa que as experiências do eu, quando inseridas em uma ordem de repetição frequente e com intensidade suficiente em muitos sujeitos de gerações sucessivas, transformam-se em experiências do id. Esses traços mnêmicos inconscientes são preservados pela herança psíquica e operarão por via do id. Este último, por sua vez, é capaz de ser herdado, e é o local que aloja os resíduos das existências e experiências constituintes de diversos eus dos ancestrais. Estas podem ser revividas inconscientemente por esse eu do descendente.

Assim, vai-se consolidando a ideia de que a condição operante dos processos psíquicos do sujeito não inclui apenas as próprias experiências, mas também elementos de origem filogenética, nos quais se incluem características da herança arcaica. Freud (1974b) propôs-se a pensar sobre três questôes 
essenciais: em que consiste essa herança, qual o seu conteúdo e como a existência dela poderia ser explicada.

A herança arcaica, de acordo com Freud (1974b), é um fator constitucional dos indivíduos que dispõe da presença de algumas características inatas encontradas em todos os organismos vivos. Porém a diferença para os seres humanos é que essa herança não abrange apenas disposições inatas, ou seja, ela não é somente filogenética, mas é também composta de traços de memória de experiências de gerações anteriores, o que faz com que extensão e importância da herança arcaica sejam consideradas significativamente.

Freud (1974b) afirma que "se presumirmos a sobrevivência desses traços de memória na herança arcaica, teremos cruzado o abismo existente entre psicologia individual e de grupo: podemos lidar com povos tal como fazemos com um indivíduo neurótico" (p. 121). São retomados agora os exemplos das leis fundamentais constituintes da civilização: a interdição do incesto e a proibição de matar o próximo. Com base neles, é possível pensar a influência que o grupo (sociedade, família) tem sobre a constituição psíquica individual do sujeito e vice-versa, considerando que tais leis se tornaram tradições entre os povos. Estas últimas são herdadas psiquicamente como algo que é posto, e não transmitidas por via da comunicação consciente.

Para explicar a existência de traços mnêmicos na herança arcaica, Freud (1974b) refere-se a situações de análise que exigem derivação filogenética. $\mathrm{O}$ autor conclui que a recordação vai se inserir na herança arcaica se o acontecimento for suficientemente importante ou repetido com alta frequência e o despertar desse traço mnêmico, que anteriormente estava esquecido por uma repetição real e recente do acontecimento, é o fator de importância decisiva para a ativação da recordação, ainda que de forma alterada e deformada na consciência. As circunstâncias para esse despertar podem estar relacionadas a vários fatores.

Até então foram apresentadas algumas das contribuições de Freud sobre o tema da transmissão psíquica para a apreensão desse assunto. Alguns achados de autores contemporâneos, discutidos a seguir, acrescentam, aprimoram e engrandecem a sustentação teórica freudiana já enunciada sobre o fenômeno da herança psíquica.

\section{Os desdobramentos da transmissão psíquica na contemporaneidade}

A transmissão psíquica entre as gerações, de acordo com Eiguer (1998), é constituída por traços mnemônicos advindos das relações dos ascendentes, 
então é algo que faria parte da pré-história do sujeito, assim como os objetos parcialmente enlutados, os quais, por exemplo, diante de uma perda que ocasionou alguma irrupção no psiquismo, não tiveram possibilidade de sofrer o processo de elaboração4 psíquica.

Kaës (1998), amparado em Freud, aponta a identificação como o principal processo da transmissão psíquica e argumenta que "o transmitido é preferencialmente o que não contém, aquilo que não se retém, aquilo de que não se lembra, como a vergonha, a falta, a doença, o recalcamento, os objetos perdidos e ainda enlutados" (p. 9). O autor denomina-os conteúdos transgeracionais.

Porém a transmissão psíquica não é composta apenas de conteúdos negativos, mas também dos conteúdos que amparam as continuidades narcísicas, que mantêm os vínculos intersubjetivos e a complexidade das formas e da vida: os ideais, mecanismos de defesa, identificações, certezas, dúvidas, entre outros, chamados de conteúdos intergeracionais (Käes, 1998). Esses dois conteúdos são herdados inconscientemente de forma simultânea, ressaltando que não há escolha do sujeito.

Kaës (1998) ainda aponta, como desdobramento da transmissão psíquica, a divisão originada da alienação. Esta pode ser compreendida como uma intrusão que ocorre a partir de desejos, lutos, perdas de outros e passam a atuar sobre o psiquismo dos descendentes. Assim, o sujeito da herança psíquica será nomeado, representado e situado em um lugar de acordo com o desejo dos porta-vozes do legado de desejos, interditos e ideais daquele determinado grupo ou família.

Toda família constrói seus mitos, e esses mitos familiares podem ser entendidos, segundo Ferreira (1963 apud Henriques e Gomes, 2005), como crenças compartilhadas inquestionáveis relativas aos sujeitos da família, seus papéis e atribuições em suas trocas. A função do mito familiar seria a de manter o grupo em concordância e, com isso, fortalecer os papéis de cada um.

Eiguer (1998) partilha da visão de Ferreira em relação ao mito familiar, acrescentando que as histórias são transmitidas às geraçóes, e isso auxilia na estabilidade do grupo, tornando-as inquestionáveis. No entanto, quando algum sujeito da família duvida de um mito, outra instância mítica instaurase, em circunstâncias suficientemente boas como os vínculos fortes dos sujeitos da família, para que haja apropriações de novas situações.

\footnotetext{
Elaboração é uma transformação do afeto (que demanda um tempo particular de cada sujeito) relativo a lembranças possivelmente traumáticas. O processo de elaboração psíquica ocorre com a análise, a partir da qual o sujeito pode construir um saber sobre si mesmo (Freud, 2010c).
} 
Para Henriques e Gomes (2005), a recusa dos mitos familiares seria a negação dos vínculos. Porém, quando o mito familiar se torna canônico, a situação é construída com a problemática de que passado e presente se misturam. Isso faz com que haja o predomínio de conteúdos transgeracionais em forma de lutos, experiências traumáticas, humilhações não metabolizados, transformados, simbolizados pelos integrantes da família das gerações passadas.

Entre os vínculos intersubjetivos das famílias, segundo Kaës (2005), há uma aliança inconsciente estabelecida de forma impositiva, denominada pacto denegativo. Este se faz presente na origem nuclear das famílias e do que está intrinsecamente relacionado a estas, como a sociedade na qual está inserida e as leis que vigoram nesta. Dessa forma, o pacto denegativo participa na constituição da subjetividade grupal e também na formação de aspectos singulares dos sujeitos, considerando que estes já nascem inseridos em um grupo primeiro: a família.

O pacto denegativo tanto participa como organizador do laço intersubjetivo como pode ser baseado em um mecanismo defensivo que diz respeito a recalcamentos, recusas e aspectos sem representação. Estes últimos não são passíveis de elaboração e irão ressurgir e retornar por meio de criptas psíquicas, estabelecendo, diante desse processo, relação com os conteúdos transgeracionais da transmissão psíquica (Garcia e Penna, 2010).

A conceituação de cripta psíquica faz menção ao "enterro intrapsíquico de uma vivência vergonhosa e indizível, traduzindo-se num fantasma de incorporação, sendo este o resultado dos efeitos de um segredo inconfessável" (Abraham e Torok, 1978 apud Ruiz Correa, 2003, p. 37). Dessa forma, entende-se que os sujeitos que tiveram criptas formadas no seu psiquismo são regidos inconscientemente em relação aos acontecimentos de outra geração, pois sua constituição psíquica foi depositária de investimentos, desejos de outros, segredos, omissões de conteúdos não elaborados pelos ancestrais.

A importância do conceito de pacto denegativo em Kaës

[...] reside no fato de que é a expressão do negativo no âmbito da intersubjetividade e se caracteriza por oferecer a cada um dos membros envolvidos aquilo que no psiquismo tem como destino o recalque, a denegação, a recusa e a rejeição. Mais ainda conduz a enquistamentos, criptas erigidas no espaço interno de um sujeito ou de um grupo (Garcia \& Penna, 2010, p. 75).

Em todas as dinâmicas de famílias, há presença tanto desses conteúdos transgeracionais quanto intergeracionais nos processo identificatórios. Silva (2003) clarifica a diferenciação entre esses conteúdos, colocando que 
os intergeracionais são compostos de vivências psíquicas elaboradas como fantasias, identificaçōes que fundam a história familiar do sujeito, de onde é extraída a essência das condições narcísicas e para a constituição de um lugar.

Os conteúdos transgeracionais, por sua vez, que podem manifestar-se como sintoma nos sujeitos da família, referem-se

[...] a um material psíquico inconsciente que atravessa diversas geraçóes sem ter podido ser transformado e simbolizado, promovendo lacunas e vazios na transmissão, impedindo uma integração psíquica. Portanto, uma herança transgeracional é constituída de elementos brutos, transmitidos tal qual, marcados por vivências traumáticas, não ditos, lutos não elaborados (Silva, 2003, p. 30).

Esse material psíquico resultante da transmissão constitui o objeto transgeracional, o qual é entendido como aquele que se coloca como objeto de outro ancestral direto ou colateral de geraçôes anteriores, que provoca fantasias, identificações, intervindo na constituição das instâncias psíquicas dos membros da família (Silva, 2003). Falta representação a esse objeto, e esse espaço de não representação vai se constituindo insuportável para o sujeito quanto mais este for impedido de compreender a origem daquilo que lhe foi investido.

Garcia e Penna (2010) acrescentam que o objeto da transmissão transgeracional manifesta-se como permanentemente intrusivo, o que faz com que o sujeito fique impossibilitado de representar, elaborar, permanecendo alienado no que diz respeito àquilo que seu psiquismo herdou, onde a vivência traumática se encripta. Esse processo conduz o sujeito à denegação, à clivagem, à repetição, "ou seja, a inscrição de uma presença ausente não se deu, [...] impedindo a criação de estruturas necessárias para o estabelecimento de distâncias e de diferenças entre gerações" (Garcia \& Penna, 2010, p. 77).

Há famílias, de acordo com Rosa (2001), em que os sujeitos pensam, de forma consciente, na possibilidade de construir um futuro independente do passado, e esse aspecto provoca falhas nos processos identificatórios relativos à transmissão psíquica. Além de a família não enfrentar situações de sofrimento, não procurando significar e elaborar as vivências traumáticas, ela ainda não revela as experiências dolorosas aos descendentes como se fosse possível ignorar os materiais inconscientes que permeiam as relações.

Ruiz Correa (2003) entende o silêncio das violências ou rupturas dos vínculos geracionais (estabelecidos pelas situações de sofrimento) assim como os mecanismos de repetição devido aos conteúdos não elaborados, como 
constituintes daquilo que gera a falta de inscrição do sujeito na sucessão das geraçôes e na família, restringindo ou impedindo o acesso aos processos de simbolização, 5 os quais organizam uma cadeia de significantes.

A partir dessas considerações e conceitos teóricos explicitados, deles se depreendeu que os processos inconscientes de transmissão psíquica ocorrem em qualquer grupo, incluindo a família, em que os conteúdos inter e transgeracionais atravessam as geraçooes. Considerando que não houve irrupção da transmissão de conteúdos transgeracionais, por meio da simbolização e elaboração destes, é possível pensar a constituição do incesto como sintoma dos processos referentes à herança psíquica transgeracional? Pode-se pensar o incesto e também suas repetições entre as gerações como vivências traumáticas oriundas de conteúdos não simbolizados que foram herdados inconscientemente pelos sujeitos que tiveram criptas instituídas no seu psiquismo?

É importante clarificar que a herança psíquica não é o fator determinante para que situações incestuosas ocorram. É uma abordagem possível de ser pensada, porém no sentido de ter uma influência sobre essa violência. Não há intento de desconsiderar outros elementos que podem propiciar o incesto, como a presença de um propenso violentador inserido na dinâmica familiar que tem total responsabilidade sobre seu ato de violência. Neste artigo também não há o propósito de argumentar questôes relativas aos violentadores, sendo esse um assunto complexo que necessita de estudos específicos para uma discussão aprofundada.

\section{Articulando a transmissão psíquica e o incesto}

É interessante comentar sobre a etimologia da palavra incesto, com base nos escritos de Cromberg (2001). A autora discorre que incesto deriva de incestum, que significa sacrilégio. Incestum origina-se de incestus, que significa impuro e sujo. Já a palavra incestus é a soma de in e cestus, sendo uma deformação de castus, que tem como significado casto, puro. Dessa forma, pode-se entender incestus também como não casto.

Razon coloca que

o incesto é um ato que infringe a intimidade corporal e psíquica de um indivíduo. Uma simples carícia basta. Definiremos, pois, o incesto como um ato de transgressão cometido sobre o corpo de uma pessoa com a qual existe uma relação de parentesco jurídico 
ou psíquico, isto é, um vínculo de sangue e/ou um vínculo simbólico (Razon, 2007, p. 8).

Cohen e Gobbetti (1998) argumentam que o incesto, um segredo familiar, acontece quando existe um vínculo familiar, que não conjugal, e ocorre a violência sexual, envolvendo membros da mesma família, sendo um dos envolvidos diretamente na situação um menor de idade, considerando a posição dos autores em relação ao conceito de família. Esta não é definida apenas por laços sanguíneos, e sim pela função social de parentesco que os membros do grupo exercem. Além disso, nota-se um envolvimento de toda a família, de forma inconsciente, na violência sexual incestuosa, pois é necessária uma dinâmica que autorize o incesto.

Ainda, de acordo com Cohen e Gobbetti (1998), é possível apreender a transgressão da proibição social de intercâmbios sexuais entre gerações de uma mesma família, considerando que essa lei da interdição do incesto é estabelecida desde a época de tribos primitivas, de acordo com a cultura em que estas estão inseridas. Lévi-Strauss (2009) também considera esse aspecto cultural na proibição do incesto. A lei da interdição funciona como uma barreira social necessária devido ao desejo incestuoso do ser humano como ser biológico. Assim, por meio da censura, tenta inserir o sujeito na cultura, tornando-o um ser social.

Sobre os processos psíquicos relativos ao incesto, Cromberg (2001) aponta este como uma situação que pode envolver todos os sujeitos integrantes de determinada dinâmica familiar (de ordem inconsciente) como construtores da cena incestuosa. Além disso, a autora estabelece algumas condições para que aconteça a violação do tabu do incesto, tais como: uma figura do grupo familiar assume um lugar que não the cabe, por exemplo, um filho que "substitui" um pai que abandonou o lar; a existência de algum grau de incompatibilidade sexual entre os cônjuges; a impossibilidade da procura de satisfação sexual fora da família; o medo da desintegração familiar e do abandono; e ainda a aceitação tácita dos outros membros da família que não constituem a dupla de incestados.

Amazonas, Oliveira e Melo (2009) também explicitam a situação incestuosa como algo que todos os sujeitos da família estão envolvidos, podendo estar diretamente implicados ou não na situação, pois, de forma consciente ou inconsciente, todos testemunham a violência em questão que precisa ser mantida em segredo para a conservação da dinâmica familiar. Isso reforçaria o mito familiar (Eiguer, 1998; Henriques e Gomes, 2005) e o pacto denegativo (Kaës, 2005) da família incestuosa. 
Henriques e Gomes (2005) apontam que, em diversas situações de violência, tanto as intrafamiliares, incluindo as agressôes sexuais, quanto as situações de violência político-social, como guerra, genocídio e miséria, denunciam um comprometimento da função de contenção e elaboração da família que experiencia determinada situação.

Diante das exposiçôes teóricas apresentadas, e para elaborar outros questionamentos, pretende-se caminhar retomando o mito da horda primeva, o qual foi discutido anteriormente. É importante recapitular que o líder do bando mantinha todo o poder para si, não permitindo que os filhos investissem libidinalmente nas mulheres do grupo, enquanto que, para o próprio líder, não havia regras ou leis nem mesmo em relação à poligamia e à prática do incesto.

Considerando a identificação como principal via dos processos de transmissão psíquica, pode-se dizer que resquícios dos traços mnemônicos desse pai foram herdados psiquicamente por esses filhos, sendo esses conteúdos armazenados no id. Pode-se pensar que a ausência de proibições engendradas nas condições de gozo do pai constituiu um objeto transgeracional e, assim, este foi transmitido?

\section{Considerações finais}

As leis fundamentais para a criação da civilização, como se foi apreendido, foram estabelecidas a partir do mito da horda primeva. Os filhos ao assassinarem o pai, devido à ambivalência de amor e ódio direcionada a este, sentiram culpa advinda da introjeção do objeto pai. Diante desses sentimentos, foi instituído que não se podia matar o pai e nem cometer incesto.

Nas histórias das famílias incestuosas, é possível pensar que, em algum momento, aconteceu algo de ordem traumática em relação ao pai simbólico, que é tido como representante da Lei. Isso pode ter contribuído para a transgressão dos tabus fundamentais, considerando que o sujeito não elaborou a angústia de castração.6 Além disso, as leis de não matar o próximo e da interdição do incesto podem ter sofrido irrupções quando transmitidas e, assim, não puderam ser simbolizadas pelos sujeitos não barrados pela Lei.

\footnotetext{
Angústia de castração, segundo Freud (1990), é um conceito que se refere a reações afetivas diante da observação e constatação da ausência do pênis. É uma experiência de amadurecimento psíquico do sujeito vivenciada, em média, aos 5 anos de idade. A angústia de castração leva à diferenciação anatômica entre os sexos, percebendo os limites do corpo e, consequentemente, à queda da onipotência narcísica, ou seja, o reconhecimento do outro também como sujeito com suas diferenças.
} 
Há casos de famílias incestuosas em que a violência se repete por geraçóes (Cromberg, 2001) e, novamente, pode-se entender a herança psíquica como um fator constituinte dessa repetição diante da não elaboração dessa experiência traumática. Por exemplo, pode-se pensar que a família não (di) menciona a vivência para os descendentes, muitas vezes por não suportar o contato com o que aconteceu. Assim, acreditam, de forma consciente, que esse é o melhor modo de lidar com a situação e, diante disso, o incesto tornase um segredo sem possibilidades de simbolização ou elaboração, como se fosse possível desconsiderar os elementos inconscientes que permanecem permeando as relaçôes daquela família. Diante disso, o mito familiar é reforçado, juntamente com o pacto denegativo, para que os vínculos e papéis dos sujeitos sejam mantidos, sejam eles quais forem.

Os desdobramentos dessa falha na simbolização provocam a construção de objetos transgeracionais que perpassam gerações, sendo depositados inconscientemente nos descendentes (sujeitos que tiveram criptas formadas no seu psiquismo). Dessa forma, com conteúdos inconscientes das gerações passadas e da atual sobrepondo-se, os sujeitos da família contemporânea (re)viverão aspectos sem representação das experiências traumáticas dos ascendentes.

A transmissão psíquica é um dos fatores que influenciam na dinâmica da família que faz evocar os fundamentos do incesto, ou seja, este pode ser, em parte, um sintoma dos legados da herança psíquica. Ainda se pode considerar que o mito familiar e o pacto denegativo também contribuem para a repetição do incesto nas gerações das famílias, já que auxiliam na manutenção dos vínculos do grupo familiar.

\section{Referências}

Amazonas, M. C. L. A., Oliveira, P. A. \& Melo, L. M. M. B. (2009). Repercussões do abuso sexual incestuoso sobre a relação mãe X filha. Psicologia em Revista, 15 (3), 82100.

Cohen, C. \& Gobbetti, G. J. (1998). Abuso sexual intrafamiliar. Revista Brasileira de Ciências Criminais, 7 (24), 235-243.

Cromberg, R. U. (2001). Cena incestuosa: abuso e violência sexual. Coleção Clínica Psicanalítica. São Paulo: Casa do Psicólogo. 
Eiguer, A. (1998). A parte maldita da herança. In: A. Eiguer. A transmissão do psiquismo entre geraçôes: enfoque em terapia familiar psicanalitica. (pp. 21-84). São Paulo: Unimarco.

Ferenczi, S. (1988). O conceito de introjeção. In: S. Ferenczi. Escritos psicanaliticos. (Joel Birman, Trad., pp. 61-63). Rio de Janeiro: Taurus. (Trabalho original publicado em 1912.)

Freud, S. (2010a). A repressão. In: S. Freud. Obras completas (Paulo César de Souza, Trad., Vol. 12, pp. 82-98). São Paulo: Companhia das Letras. (Texto original publicado em 1915.)

Freud, S. (2010b). "Batem numa criança": Contribuiçãoo ao conhecimento da gênese das perversōes sexuais. In: S. Freud. Obras completas (Paulo César de Souza, Trad., Vol. 14, pp. 293-327). São Paulo: Companhia das Letras. (Texto original publicado em 1919.)

Freud, S. (1974a). Estudos sobre a histeria. In: S. Freud. Edição standard das obras psicológicas completas de Sigmund Freud (J. Salomão, Trad., Vol. 2, pp. 15-319). Rio de Janeiro: Imago. (Texto original publicado em 1895.)

Freud, S. (1974b). Moisés e o monoteísmo: três ensaios. In: S. Freud. Edição standard das obras psicológicas completas de Sigmund Freud (J. Salomão, Trad., Vol. 23, pp. 14-161). Rio de Janeiro: Imago. (Texto original publicado em 1939.)

Freud, S. (2011a). O Eu e o Id. In: S. Freud. Obras completas (Paulo César de Souza, Trad., Vol. 16, pp. 13-74). São Paulo: Companhia das Letras. (Texto original publicado em 1923.)

Freud, S. (2010c). Introdução ao narcisismo. In: S. Freud. Obras completas (Paulo César de Souza, Trad., Vol. 12, pp. 13-50). São Paulo: Companhia das Letras. (Texto original publicado em 1914.)

Freud, S. (2011b). Psicologia das massas e Análise do Eu. In: S. Freud. Obras completas (Paulo César de Souza, Trad., Vol. 15, pp. 13-113). São Paulo: Companhia das Letras. (Texto original publicado em 1921.)

Freud, S. (1990). Recordar, repetir e elaborar. In: S. Freud. Edição standard das obras psicológicas completas de Sigmund Freud (J. Salomão, Trad., Vol. XII, pp. 189203). Rio de Janeiro: Imago. (Texto original publicado em 1914.)

Freud, S. (1974c). Totem e tabu. In: S. Freud. Edição standard das obras psicológicas completas de Sigmund Freud (J. Salomão, Trad., Vol. 13, pp. 13-191). Rio de Janeiro: Imago. (Texto original publicado em 1913.) 
Garcia, C. A. \& Penna, C. M. P. e A. (2010). O trabalho do negativo e a transmissão psíquica. Arquivos Brasileiros de Psicologia, 62 (3), 68-79.

Henriques, M. I. G. \& Gomes, I. C. (2005). Mito familiar e transmissão psíquica: uma reflexão temática de forma lúdica. Psychê Revista de Psicanálise, 9 (16), 183-196.

Kaës, R. (1998). Os dispositivos psicanalíticos e as incidências da geração. In: A. Eiguer. A transmissão do psiquismo entre geraçôes: enfoque em terapia familiar psicanalítica. (pp. 5-19). São Paulo: Unimarco.

Kaës, R. (2005). Os espaços psíquicos compartilhados: transmissão e negatividade. São Paulo: Casa do Psicólogo.

Lévi-Strauss, C. (2009). As estruturas elementares do parentesco. Petrópolis: Vozes. (Trabalho originalmente publicado em 1949.)

Razon, L. (2007). Enigma do incesto. Rio de Janeiro: Companhia de Freud.

Roudinesco, E. \& Pilon, M. (1998). Dicionário de Psicanálise. Rio de Janeiro: Jorge Zahar. (Trabalho original publicado em 1944.)

Rosa, M. D. (2001). O não dito familiar e a transmissão da história. Psychê Revista de Psicanálise, 5 (8), 123-137.

Ruiz Correia, O. B. (2003). A transmissão psíquica entre gerações. Psicologia USP, 14(3), 35-45.

Silva, M. C. P. da (2003). A herança psíquica na Clínica Psicanalítica. São Paulo: Casa do Psicólogo. 